\title{
Subchronic Alpha-Linolenic Acid Treatment Enhances Brain Plasticity and Exerts an Antidepressant Effect: A Versatile Potential Therapy for Stroke
}

\author{
Nicolas Blondeau*, I,2, Carine Nguemeni', David N Debruyne', Marie Piens ${ }^{3}$, Xuan $\mathrm{Wu}^{4}$, Hongna Pan ${ }^{4}$, \\ XianZhang $\mathrm{Hu}^{4}$, Carine Gandin' ${ }^{1}$, Robert $\mathrm{H}_{\text {Lipsky }}{ }^{5,6}$, Jean-Christophe Plumier ${ }^{3}$, Ann M Marini ${ }^{4}$ and \\ Catherine Heurteaux ${ }^{1,2}$
}

'Cerebrovascular Pathologies and Therapeutic Laboratory, Institut de Pharmacologie Moléculaires et Cellulaires - UMR6097, C.N.R.S, Valbonne, France; ${ }^{2}$ Department of Neuroscience, University of Nice Sophia Antipolis, Nice Cedex 2, France; ${ }^{3}$ Physiologie Animale, University of Liège, Liège, Belgium; ${ }^{4}$ Department of Neurology and Neuroscience Program, Uniformed Services University of the Health Sciences, Bethesda, MD, USA; ${ }^{5}$ Department of Neurosciences, Inova Health System, Inova Fairfax Hospital, Falls Church, VA, USA; ${ }^{6}$ Department of Molecular Neuroscience, Krasnow Institute for Advanced Study, George Mason University, Fairfax, VA, USA

\begin{abstract}
Omega-3 polyunsaturated fatty acids are known to have therapeutic potential in several neurological and psychiatric disorders. However, the molecular mechanisms of action underlying these effects are not well elucidated. We previously showed that alpha-linolenic acid (ALA) reduced ischemic brain damage after a single treatment. To follow-up this finding, we investigated whether subchronic ALA treatment promoted neuronal plasticity. Three sequential injections with a neuroprotective dose of ALA increased neurogenesis and expression of key proteins involved in synaptic functions, namely, synaptophysin- I, VAMP-2, and SNAP-25, as well as proteins supporting glutamatergic neurotransmission, namely, V-GLUTI and V-GLUT2. These effects were correlated with an increase in brain-derived neurotrophic factor (BDNF) protein levels, both in vitro using neural stem cells and hippocampal cultures and in vivo, after subchronic ALA treatment. Given that BDNF has antidepressant activity, this led us to test whether subchronic ALA treatment could produce antidepressant-like behavior. ALA-treated mice had significantly reduced measures of depressive-like behavior compared with vehicletreated animals, suggesting another aspect of ALA treatment that could stimulate functional stroke recovery by potentially combining acute neuroprotection with long-term repair/compensatory plasticity. Indeed, three sequential injections of ALA enhanced protection, either as a pretreatment, wherein it reduced post-ischemic infarct volume $24 \mathrm{~h}$ after a I-hour occlusion of the middle cerebral artery or as post-treatment therapy, wherein it augmented animal survival rates by threefold 10 days after ischemia. Neuropsychopharmacology (2009) 34, 2548-2559; doi:I 0. I038/npp.2009.84; published online 29 July 2009
\end{abstract}

Keywords: alpha-linolenic acid; stroke; neurogenesis; synaptogenesis; BDNF; antidepressant effects

\section{INTRODUCTION}

Post-stroke depression (PSD) represents a large portion of the cost spent on the disabilities associated with stroke in the United States (US Department of Health and Human Services, 1999). The estimated prevalence of PSD ranges from 25 to 79\% (Gordon and Hibbard, 1997) and is often not detected or inadequately treated (Jia et al, 2006). Stroke patients with PSD suffer higher mortality rates and show only minor improvement in rehabilitation programs, resulting in worse functional (motor and cognitive) out-

*Correspondence: $\operatorname{Dr} N$ Blondeau, Institut de Pharmacologie Moléculaires et Cellulaires, UMR6097, C.N.R.S, Valbonne 06560, France, Tel: + 334939577 40, Fax: + 334939577 08,

E-mail: blondeau@ipmc.cnrs.fr

Received 14 January 2009; revised 12 June 2009; accepted 12 June 2009 comes and poorer quality of life (Jorge et al, 2003). Stroke and depression are known to be heterogeneous and multifactorial disorders, but they share common pathological substrates accessible to multitarget strategies. For example, there is increasing evidence that neural plasticity has a key role in both pathologies. Thus, substances that enhance plasticity in the brain could attenuate or reverse their adverse effects and improve the outcome.

In a related disorder, that is, major depressive disorder (MDD), epidemiological and clinical studies suggest that the consumption of omega-3 fatty acids is inversely correlated to the prevalence and the severity of MDD, and that an omega-3 supplementary diet induces benefits in the treatment of depressive states (Hibbeln, 1998; Peet et al, 1998). Thus, omega-3 polyunsaturated fatty acids (PUFA) are good candidates for neuronal protective and restorative strategies against depressive states. In normal mice, chronic administration of a PUFA-supplemented diet consisting of 
alpha-linolenic acid (ALA), linoleic acid, and oleic acid exerted antidepressant-like effects. These behavioral effects were associated with increases in synaptogenesis, cell number, brain-derived neurotrophic factor (BDNF) gene expression, and hippocampal volume (Venna et al, 2009).

In the domain of stroke disorders, there is growing evidence that the omega-3 precursor, ALA, is a potent protector in several models of global and focal ischemia (Xiao et al, 1998; Lauritzen et al, 2000; Blondeau et al, 2001, 2002, 2007; Lang-Lazdunski et al, 2003; Heurteaux et al, 2004, 2006a). In a mouse model of stroke, we found that a single injection of ALA, after the onset of stroke, significantly reduced infarct size and improved the neurological score 24 -h post-ischemia. Although the single injection of ALA did not improve long-term survival rate, repeated ALA injections over 3 weeks significantly improved survival, suggesting that subchronic ALA treatment triggers other protective pathways (Heurteaux et al, 2006a).

The aims of the present study were to determine whether subchronic ALA treatment could (1) specifically increase neuronal plasticity at the molecular and cellular level, (2) produce antidepressant-like behavior, and (3) reduce stroke-induced mortality. We also sought to determine the effect of ALA pretreatment on neuronal loss in vitro and in vivo.

\section{MATERIALS AND METHODS}

\section{Animals}

All experiments were performed according to policies on the care and use of laboratory animals by European Community legislation. Adult male C57/Bl6 mice, weighing $24 \pm 2 \mathrm{~g}$ were used in this study. The animals were housed with free access to food and water for 1 week before pharmacological treatment or surgery.

\section{Experimental Protocol of Drug Administration}

The experimental protocol is shown in Figure 1a (left side). It includes the study on 'the effect of single or repeated ALA injections on neurogenesis' as three experimental stages.

In the first stage, mice received a single ALA injection $(500 \mathrm{nmol} / \mathrm{kg} ; \mathrm{ALA500})$ and were injected with 5-bromo-2'deoxyuridine (BrdU) $(2 \times 300 \mathrm{mg} / \mathrm{kg}$, IP) on day 2 (D2) and D3. BrdU-positive cells were counted 3 days after the single ALA500 injection. In the second stage, mice received three injections of ALA500 on D1, D3, and D7 (called subchronic treatment). Then, mice were injected with BrdU on D9 and D10. BrdU-positive cells were counted 10 days after the onset of the multi-injection ALA500 treatment (D10). In the third stage, mice received the same subchronic ALA treatment (on D1, D3, and D7) and BrdU-positive cells were counted at D31 to allow the proliferative (BrdUpositive) cells to survive and become neurons. ALA doses used were selected based on our previous studies in the mouse model of focal ischemia (Heurteaux et al, 2006a) and from pilot studies, in which we sought to find the best longterm protection. Compared with three injections on D1, D2, and D3, subchronic treatment with ALA500 on D1, D3, and D7 resulted in improved survival and protection on D31 (data not shown).

\section{Determination of Neurogenesis}

Newborn cell assessment. Paraformaldehyde-perfused brains were sectioned ( $40 \mu \mathrm{m}$ thick) through the entire hippocampus on a vibratome (Leica, Rueil Malmaison, France). Every sixth section throughout the hippocampus was processed for immunohistochemistry (Heurteaux et al, $2006 \mathrm{~b})$ using a monoclonal mouse anti-BrdU (1/200; BD Biosciences, Le pont de Claix, France) antibody, according to the protocol described previously (Tang et al, 2007). BrdU-labeled cells of granular and subgranular layers were counted in each section ( $n=10$ mice per group) at $\times 400$ under a light microscope by two investigators who were blinded to treatment groups.

Neurogenesis assessment. The phenotype of the BrdUpositive cells was determined using fluorescent doublelabeling using the following antibodies and dilutions: anti-sheep BrdU (1/200, Interchim, Montluçon, France), anti-goat DCX (doublecortin, 1/200, Santa Cruz Laboratories, Heidelberg, Germany), anti-mouse NeuN (neuronspecific nuclear protein, 1/250, Millipore, St Quentin en Yvelines, France), GFAP (Glial Fibrillary Acidic Protein, $1 / 250$, Dako cytomation, Trappes, France), and secondary antibodies conjugated with Alexa Fluor 488 or 594 (1/1000; Molecular Probes, Leiden, Netherlands). Confocal microscopy were performed using a Laser Scanning Confocal Microscope (TCS SP, Leica).

\section{Western Blot Analysis for Neurotrophin, Brain Plasticity, and Synaptogenesis}

Western blot analyses were performed using $50 \mu \mathrm{g}$ proteins from the whole cortex, hippocampus, or striatum $(n=6$ per group) (Blondeau et al, 2002). Briefly, proteins were fractionated through $12 \%$ SDS-PAGE gels and transferred to Hybond-P PVDF membranes (GE Health care life sciences, Orsay, France) before incubation with the following antibodies and dilutions: anti-BDNF (1/200, Chemicon International, Hampshire, UK), anti-DCX (1/200, Santa Cruz Biotechnology), anti-synaptophysin-1, anti-synaptobrevin-2, anti-SNAP-25, anti-V-GLUT-1, and anti-V-GLUT2, (1/10000, Synaptic Systems, Göttingen, Germany). Stripped membranes were rehybridized with a $\alpha$-tubulin antibody (Sigma-Aldrich, Isle d'Abeau Chesnes, France) to control for sample loading. Immunoreactive proteins were visualized using ECL plus western blotting detection reagents (Millipore) with a Las-3000 imaging system (Fujifilm Life Science-FSVT, Courbevoie, France).

\section{ALA-Mediated Neuroprotection Against Glutamate Excitotoxicity In Vitro}

Hippocampal cultures were prepared from embryonic day 18 to 20 (E18-20) Sprague-Dawley rat embryos (Jiang et al, 2005). Briefly, hippocampi were placed into ice-cold Hank's solution with $1 \mathrm{mM}$ HEPES and $1 \mu \mathrm{l} / \mathrm{ml}$ penicillin-streptomycin. The tissues were trypsinized and treated with soybean trypsin inhibitor $(2 \mathrm{mg} / \mathrm{ml})$ in $10 \mathrm{ml}$ Hank's solution and incubated at $37^{\circ} \mathrm{C}$ for $5 \mathrm{~min}$. The tissues were then diluted with MEM to achieve a seeding density of $250000 \mathrm{cells} / \mathrm{ml}$ in poly D-lysine pre-coated Nunc dishes 
$(50 \mu \mathrm{g} / \mathrm{ml})$. On day in vitro (DIV) 3 , and every other day thereafter, one-fifth of the culture medium was removed and replaced with fresh media. Cultures were used between DIV 7 and 8. Neurons were fully susceptible to the neurotoxic effects of glutamate acting on NMDA receptors by DIV 8 .

Hippocampal neurons were treated with $100 \mu \mathrm{M}$ ALA, a concentration known to be protective both in vivo and in vitro on granule cells (Lauritzen et al, 2000), for $24 \mathrm{~h}$. BDNF levels were determined by enzyme-linked immunosorbent assay (ELISA) (below). In other experiments, ALA $(100 \mu \mathrm{M})$ was added $30 \mathrm{~min}$ before the addition of an excitotoxic concentration of glutamate $(50 \mu \mathrm{M})$ for $24 \mathrm{~h}$. Viable neurons in pre-marked microscopic fields were counted before and $24 \mathrm{~h}$ after exposure to glutamate. Neurons from triplicate dishes were counted in four microscopic fields in each experimental group.

\section{Neural Stem Cell Culture, Proliferation, and Differentiation}

Primary cultures of Neural Stem Cells (NSCs) were obtained from E16 mouse embryos. Isolated brain and striata were extracted in DPBS (Dulbecco's phosphate-buffered saline, Invitrogen) supplemented with $0.45 \%$ glucose. Striata were mechanically dissociated by two successive triturations and sedimentation steps were performed in DMEM/F12 medium supplemented with B-27 and EGF (20 ng/ml) (Invitrogen). The cell suspension was filtered through a $15-\mu \mathrm{m}$ nylon cell strainer. Primary floating neurosphere colonies were subcloned 3 days later by mechanically dissociating a single neurosphere colony in B27-supplemented DMEM/F12 medium containing EGF $(20 \mathrm{ng} / \mathrm{ml})$, and plated in uncoated culture plates at a density of $10^{6}$ cells per $20 \mathrm{ml}$. After 3 days, when the diameter of the secondary neurospheres was above $30 \mu \mathrm{m}$, NSCs were incubated with $100 \mu \mathrm{M}$ ALA for 3 days and used for BDNF reverse transcriptase PCR (RTPCR) and proliferation assay.

NSC proliferation was assessed by immunocytochemistry using the nuclear protein Ki-67, which is expressed by the proliferating cells. To this end, NSCs were again dissociated by trituration, filtered, and plated on poly-ornithine-coated coverslips. NSCs were fixed and permeabilized/blocked in TBS, BSA $1 \%$, Triton-X100 0.1\%. NSCs were then stained using an anti-mouse Ki-67 antibody (BD Biosciences), detected with a fluorescent secondary anti-mouse antibody, and mounted in Vectashield HardSet Mounting Medium with DAPI (Clinisciences). Ki-67-positive cells were expressed as percentage of total number of NSCs showing DAPI staining.

For the study of the synaptogenesis marker SNAP-25, secondary neurospheres were plated on poly-ornithinecoated plates. After 3 days, when the differentiation process had started, ALA was added to the medium for 3 days.

\section{BDNF ELISA and RT-PCR Assays}

To detect the form of BDNF protein, the quantitative twosite enzyme immunoassay was performed using a two-site ELISA system (Promega, Madison, WI). For in vitro experiments, neurons were treated in the presence or absence of $100 \mu \mathrm{M}$ ALA. Total intracellular BDNF protein levels were determined $24 \mathrm{~h}$ later (Jiang et al, 2005). For in vivo experiments, BDNF protein levels were determined at D10.

PCR amplification was carried out with 20 pmol of the following primers: For BDNF exon 1 to exon 7 mRNA: $5^{\prime}$ AAGCCGAACTTCTCACATGA- $3^{\prime}$ and $5^{\prime}$-TGCAACCGAAG TATGAAATAACCATAG-3' and for the glyceraldehyde-3phosphate dehydrogenase (GAPDH): 5'-ACCACAGTC CATGCCATCAC-3' and 5'-TCCACCACCCTGTTGCTGTA$3^{\prime}$. PCR conditions for each set of primers were $95^{\circ} \mathrm{C}$ for $5 \mathrm{~min}$, followed by 33 cycles at $94^{\circ} \mathrm{C}$ for $3 \mathrm{~min}, 94^{\circ} \mathrm{C}$ for $1 \mathrm{~min}, 54^{\circ} \mathrm{C}$ for $1 \mathrm{~min}, 72^{\circ} \mathrm{C}$ for $30 \mathrm{~s}$, and $72^{\circ} \mathrm{C} 10 \mathrm{~min}$. Results were expressed as a ratio of BDNF/GAPDH for seven different NSC cultures.

\section{Middle Cerebral Artery Occlusion}

Occlusion of the left middle cerebral artery (MCAO) was performed (Heurteaux et al, 2006a), using a 6-0 coated filament (Doccol, Redlands, CA). The regional cerebral blood flow was monitored by laser-Doppler flowmetry (Perimed, Craponne, France) to control MCAO severity and reperfusion. In the pretreatment study, mice received an injection of $500 \mathrm{nmol} / \mathrm{kg}$ ALA (ALA500) given on D1, D3, and $\mathrm{D} 7$ before ischemia (Figure $5 \mathrm{~d}$ ). MCAO was performed at D10 and the infarct volume was quantified at 24 -h postischemia. In the post-treatment study, MCAO was performed at D1 and mice received a single ALA500 injection $2 \mathrm{~h}, 3$ and 7 days after MCAO (Figure 5e). The mortality rate was analyzed at 10 days post-ischemia to compare the protective efficiency of subchronic ALA treatment with a single ALA500 injection, given 2-hrs post-MCAO. The protocol and dose were selected on the basis of our previous studies (Lauritzen et al, 2000; Blondeau et al, 2001, 2002; Lang-Lazdunski et al, 2003; Heurteaux et al, 2004, 2006a). ALA and its vehicle (Biomol, Exeter, UK) were injected as a bolus in the tail vein. Sham-operated animals for the MCAO experiments and vehicle-injected mice were used as controls.

To assess the infarct volume, mice were killed at $24 \mathrm{~h}$ after reperfusion. Coronal frozen sections of brain $(20 \mu \mathrm{m}$-thick) were stained using a solution of $1 \%$ cresyl violet in $0.25 \%$ acetic acid, and mounted with Entellan. The striatal and cortical areas of infarction, outlined in light were measured on each section using a computer image analysis system and corrected for brain edema according to Golanov and Reis (1995). Infarct volume, expressed in $\mathrm{mm}^{3}$ was calculated by a linear integration of the corrected lesion areas, as previously described (Heurteaux et al, 2006a).

\section{Behavioral testing}

Two different sets of mice have been used for behavioral tests at $1 \mathrm{~h}$, and on D7 and D10.

Porsolt forced swim test (FST) is a model of behavioral despair. Groups of mice (vehicle and ALA-treated) were individually placed into a glass cylinder (height of $30 \mathrm{~cm}$, diameter of $15 \mathrm{~cm}$ ) filled with $15 \mathrm{~cm}$ of water at $22 \pm 1^{\circ} \mathrm{C}$ for $6 \mathrm{~min}$. Blind investigators measured the duration of immobility of the last $4 \mathrm{~min}$ (Heurteaux et al, 2006b).

Tail suspension test (TST, Bioseb, Vitrolles, France). Mice (vehicle and ALA-treated) were suspended for $6 \mathrm{~min}$ by 
the tail and the immobility time accepted to mirror a state of depression was measured. FST and TST are both commonly accepted to predict antidepressant efficiency (Porsolt et al, 1977).

Locomotor activity: Mice were placed in activity cages in which photoelectric cells were inserted, allowing recordings of locomotion, that is, quantification of the total number of activity counts (photocell beam breaks) during $24 \mathrm{~h}$ (Imetronic, Pessac, France).

\section{Statistical Analyses}

Data were expressed as mean \pm SEM. Statistical analysis of differences between groups was performed by using unpaired $t$-test or ANOVA. Where F ratios were significant, statistical analyses were extended and post-hoc comparisons were made by using Tukey's test for multiple comparison tests. The level of significance was set at $p<0.05$.

\section{RESULTS}

Subchronic ALA Treatment Induces Neurogenesis in the Hippocampus

Incorporation of the DNA synthesis marker, BrdU, into the DNA of dividing progenitor cells has been often used to show that several neuroprotective drugs or paradigms, such as ischemic preconditioning, increase adult neurogenesis (Yoshimura et al, 2001; Naylor et al, 2005). Using the same approach, we found that the majority of the BrdU-positive cells were located in the subgranular zone of the dentate gyrus (SGZ), a known brain region of adult neurogenesis corresponding to the production of newborn neurons (Figure 1a, right panel). At three days after a single ALA500 injection (D3), the number of dentate gyrus BrdU-positive cells $(886 \pm 69)$ increased relative to vehicletreated animals $(676 \pm 79)$, although the difference was not significant $(p>0.05$, Figure 1a right panel). In contrast, when mice were treated with three sequential ALA500 injections and the level of neurogenesis analyzed 3 days later (corresponding to D10), neurogenesis was significantly increased. The number of BrdU-positive cells was of $946 \pm 75$ as compared with $626 \pm 46$ in the vehicle-injected mice $(p \leqslant 0.001$, Figure 1a). BrdU-positive cells counted on D31 (3 weeks after the last BrdU injection) showed that the increase of BrdU cells was maintained. ALA treatment induced a 1.6-fold increase $(203.2 \pm 21$ in vehicle- $v s$ $327 \pm 16$ in ALA-treated mice).

To determine whether the proliferating cells were characterized as immature neurons, we investigated whether DCX was co-localized with the BrdU-positive cells in the SGZ. DCX is a microtubule-associated protein that is specifically expressed in all migrating neuronal precursors and in areas of continuous neurogenesis. Representative confocal microscopy images taken on D10 show that the increase in DCX was co-localized in BrdU-labeled cells in the ALA500-treated animals (three injections) as compared with vehicle-treated mice (Figure 1b). A slight but nonsignificant increase in the percentage of BrdU-DCXpositive cells in ALA500-injected mice $(43.1 \pm 10.4 \%)$ as compared with vehicle-injected mice $(25.4 \pm 3.6 \%)$ was found 3 days after a single ALA500 injection (D3). However,
3 days after the end of the complete ALA500 treatment (subchronic ALA treatment and analysis on D10), we observed a significant increase in the level of neurogenesis (that is, the number of new dividing cells) that corresponded to a significant 1.74 -fold increase in the number of neuronal progenitor cells expressing DCX $(n=5, p<0.001)$.

We then investigated whether the strong increase in neuronal precursors at D10 induced by three ALA 500 injections correlated with an increase in neuronal maturation, as determined by the mature neuron marker, NeuN. There was no co-localization of BrdU and NeuN proteins in both ALA and vehicle treatments (data not shown), suggesting that the neuronal maturation process had not started. As newborn cells need about 3 weeks to differentiate into mature neurons, a lack of immunoreactive NeuN was predicted. Furthermore, these newborn cells did not express the astrocyte marker, GFAP, in the dentate gyrus of ALA500-treated mice, providing evidence that the cells differentiated into neurons (data not shown). However, by D31, the number of mature neurons (BrdU/NeuN-positive cells) increased significantly, 1.54-fold, after subchronic ALA treatment (Figure 1d).

\section{Subchronic ALA Treatment Triggers In Vivo BDNF Expression}

Neurotrophic factors, including BDNF, influence neurogenesis, and it is well known that BDNF-mediated pathways are involved in cell survival and plasticity ( $\mathrm{Lu}$ and Figurov, 1997; Mattson et al, 2003). For this reason, we investigated whether subchronic ALA treatment could trigger BDNF expression on D10. Figure 2 shows the in vivo effect of subchronic ALA500 treatment on BDNF protein levels in hippocampus, striatum, and cortex on D10. Western blot analysis revealed no significant changes in mature BDNF levels in the striatal samples $(99.6 \pm 18.5 v s 101.5 \pm 18.9$ for ALA and vehicle-injected mice, respectively, $p>0,05$ ) (Figure 2a). In contrast, a significant 2.9-fold increase in mature BDNF protein levels was observed in the hippocampal area $(p<0.05)$. Furthermore, a significant 2.3 -fold increase of mature BDNF protein levels was also observed in cortex $(p<0.05)$. The cortical BDNF protein upregulation was confirmed by the BDNF ELISA (Figure $2 \mathrm{~b}$ ), showing a $30 \%$ increase in the total BDNF protein content between the vehicle and ALA treatment on D10 $(p<0.05)$.

\section{ALA Treatment Triggers In Vitro BDNF Expression and Promotes NSC Proliferation and Synaptogenesis}

To ascertain a direct link between ALA treatment and BDNF upregulation in neurons, we tested the in vitro ALA effect on hippocampal neurons. Knowing that an ALA concentration of $100 \mu \mathrm{M}$ was protective against excitotoxic cell death in granule neurons (Lauritzen et al, 2000), we determined levels of mature BDNF in hippocampal neurons after ALA treatment. Application of ALA $(100 \mu \mathrm{M})$ to hippocampal neurons increased total BDNF protein levels by nearly $50 \%$ $(p<0.01)$ (Figure 3a).

Our in vivo results suggested that ALA promotes NSC proliferation. To establish a direct effect of an ALA treatment on NSCs, we tested whether ALA, at a known neuroprotective concentration $(100 \mu \mathrm{M})$, promotes NSC 
a
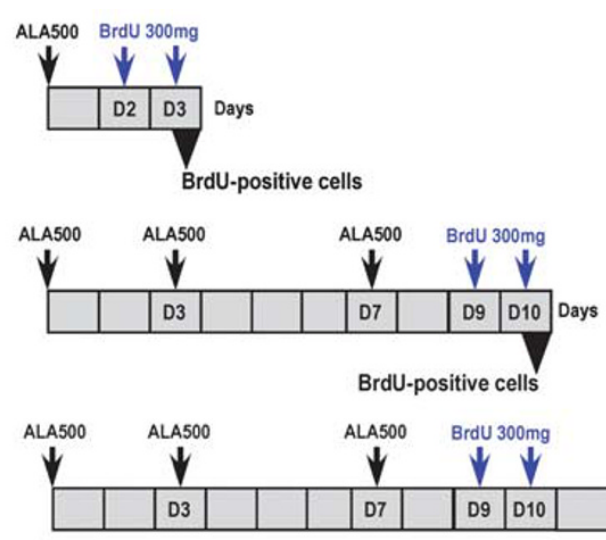

b
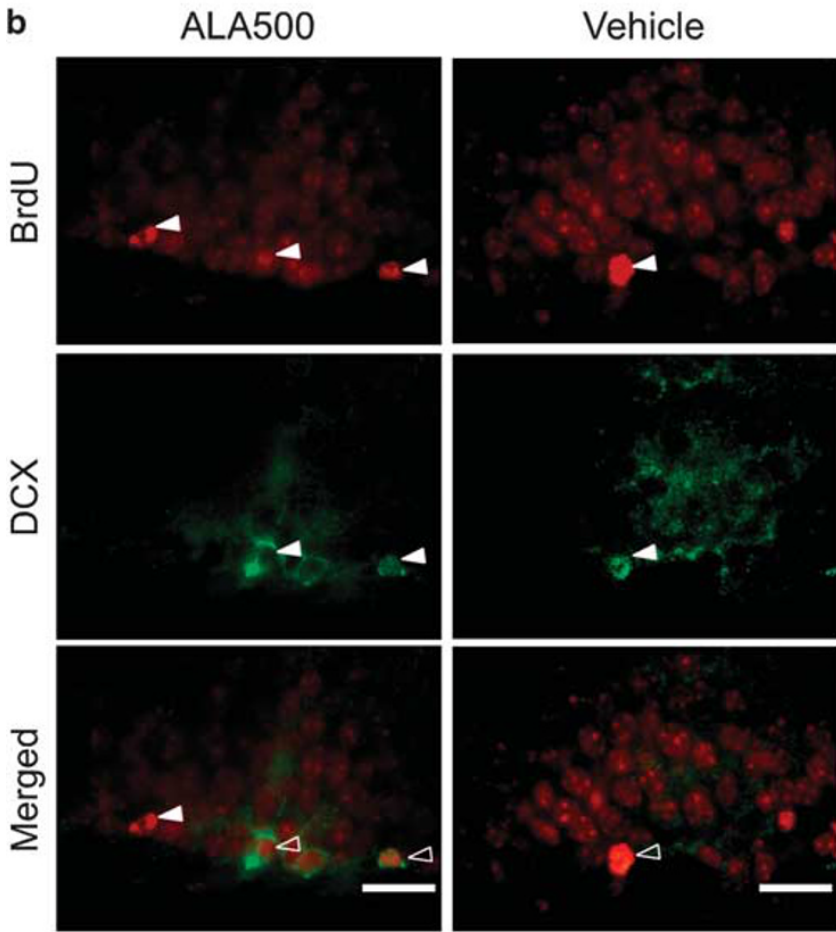

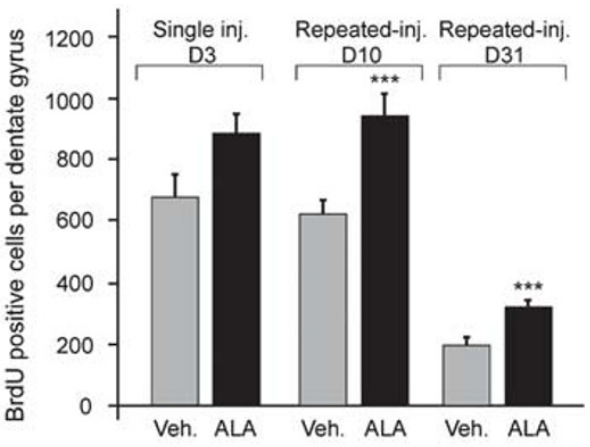

031

BrdU-positive cells
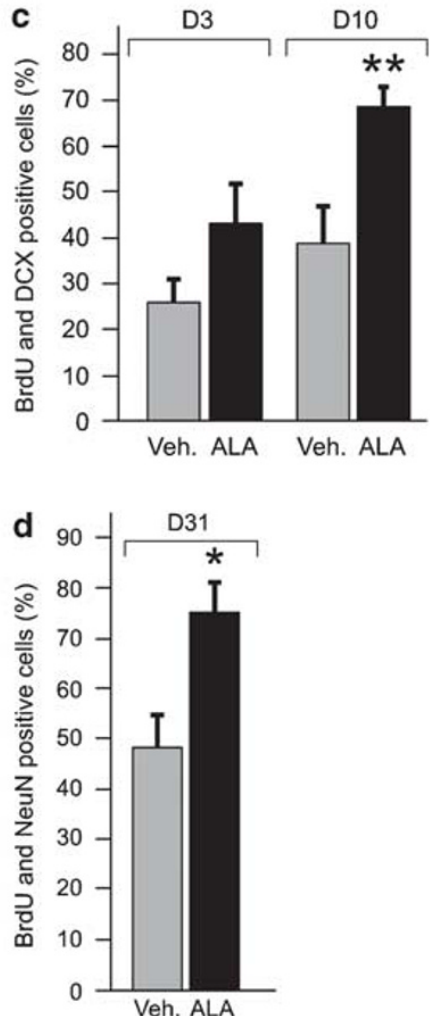

Figure I Effect of subchronic ALA treatment on neurogenesis. (a) Effect of single or repeated ALA injections on cell proliferation. Left panel displays the three stages of experimental design consisting of (I) a single ALA injection analyzed on day 3 (D3) and (2)/ ALA injections administered on days I, 3, and 7 before analysis on DI0, (3) ALA injection administered on days I, 3, and 7 before analysis on D3I. In the three cases, mice were injected with BrdU on the last two days of the experiment. Right panel displays the number of BrdU-positive cells in the left and right dentate gyrus in the three different paradigms. (b) Representative confocal images showing an increase in the BrdU-labeled cells co-localized with DCX, a marker of immature neurons in the SGZ of ALAtreated mice, compared with vehicle-treated mice at Day 10. Red immunofluorescence: BrdU, Green immunofluorescence: DCX. Open and closed arrows display - and + co-labeled cells, respectively. Scale bar is $20 \mu \mathrm{m}$. (c) Histogram showing the percent of BrdU-positive cells that were also DCX-positive. Data represents the number of DCX-BrdU-positive cells in the dentate gyrus ( $n=5$ per group), expressed as means \pm SEM. *** $\leqslant \leqslant 0.0$ I vs vehicle-treated mice. (d) Histogram showing the percentage of BrdU-positive cells that were also NeuN-positive at Day $3 \mid$ ( $n=I 0$ per group), expressed as means \pm SEM. $* p \leqslant 0.05$ vs vehicle-treated mice. $* * * * \leqslant 0.00$ I vs vehicle-treated mice.

proliferation in culture. Few NSCs were growing in the vehicle conditions, whereas NSCs were more abundant after ALA treatment (Figure $2 \mathrm{~b}$ ). This observation was confirmed by immunohistochemistry using $\mathrm{Ki}-67$ nuclear protein staining, the expression of which is strictly associated with cell proliferation and is routinely used as a proliferation marker (Wada et al, 2006; Maysami et al, 2008). Indeed, after 3 days of ALA treatment, a nearly 1.6-fold increase in the percentage of Ki-67-positive NSCs was seen $(36.5 \pm 2.9 \%$ of Ki-67-positve NSCs reached $58.1 \pm 3.3 \%$ in presence of $100 \mu \mathrm{M}$ ALA, $p<0.001$ ), clearly indicating an increase in cell division and marked NSC proliferation (Figure 3c, right panel).

Neuronal stem cells are known to induce BDNF gene transcription to modify the ischemic environment and to promote neuroprotection. To explore a mechanism by 


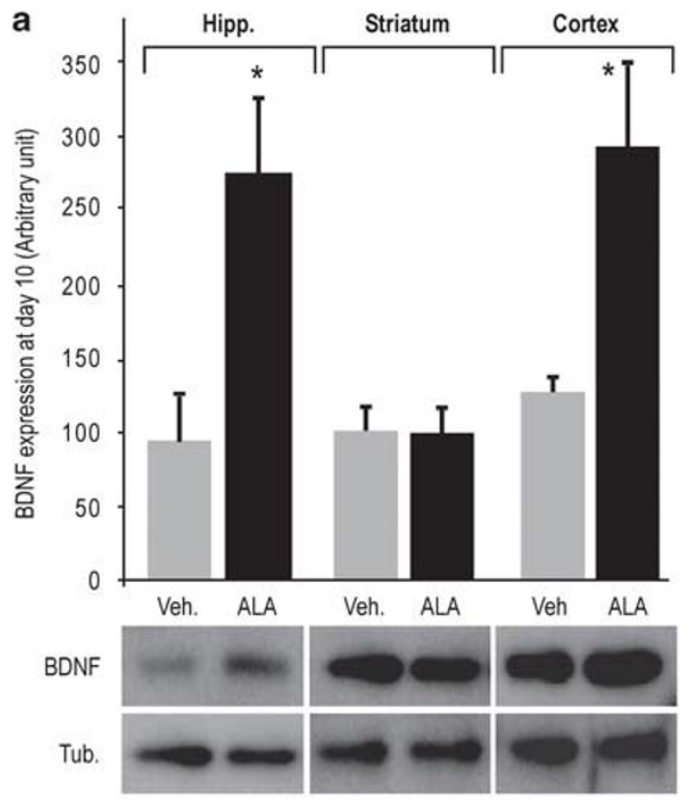

b

BDNF levels ( $\mathrm{pg} / \mathrm{\mu g}$ protein)

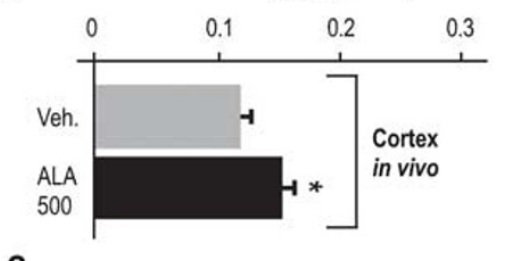

c

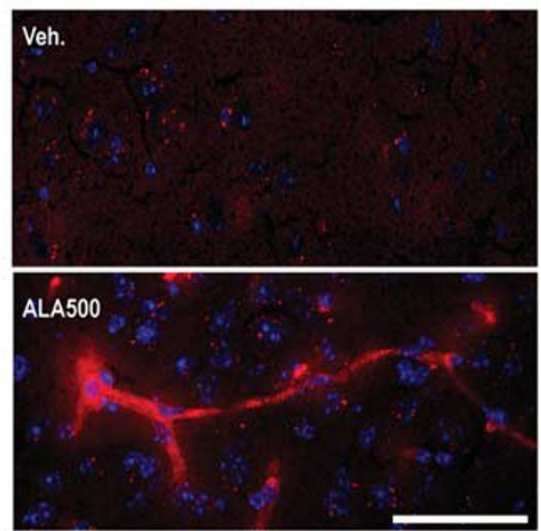

Figure 2 In vivo effect of subchronic ALA treatment on BDNF protein levels. (a) ALA treatment induced BDNF levels in mature neurons of the cortex and hippocampus in vivo. Mature BDNF expression detected by Western blots in cortex, hippocampus $(* p<0.05)$, and striatum ( $p>0.05)$ of animals injected with ALA or vehicle. (b) Increased BDNF protein levels under ALA treatment detected by ELISA in cortical neurons. (c) Immunostaining for SNAP25, a synaptosome-associated exocytosis protein in the cortex of ALA500-treated animals at day 10.

which ALA affects NSC proliferation, we determined whether BDNF mRNA levels were altered by ALA treatment. Interestingly, a 3-day ALA treatment results in a 3.6-fold increase in BDNF mRNA levels $(p<0.001)$ (Figure $3 c$, left panel).

Brain-derived neurotrophic factor is associated with increased synapse formation and synaptic transmission (Alsina et al, 2001; Huang and Reichardt, 2001). Therefore, our discovery that in vivo and in vitro newborn neuron proliferation and BDNF upregulation are activated by ALA subchronic treatment, suggests that ALA may alter synaptic plasticity. We investigated the in vitro and in vivo expression of SNAP-25, a $25-\mathrm{kDa}$ synaptosome-associated exocytosis protein that has an important role in the secretory pathway. Application of ALA $(100 \mu \mathrm{M})$ increases SNAP-25 protein level in NSCs, which is shown by immunoblot analysis (Figure $3 \mathrm{~d}$ ). In parallel, a robust upregulation of SNAP-25 was found in the cortex of ALA500-treated animals on D10 (Figure 2c).

\section{ALA Treatment Modulates Synaptic Vesicle Fusion and Synapse Function Protein Levels}

We next studied the effect of in vivo ALA500 treatment, at D10, on different proteins having critical roles in synaptogenesis and synapse function, such as the vesicle fusion proteins (SNAREs) and the vesicular glutamate transporters (V-GLUTs).

To test the hypothesis that an increase in synaptogenesis occurs in ALA-treated animals, we used a monoclonal antibody to synaptophysin-1, which is considered as a marker for synapses during neuronal development and commonly used to analyze presynaptic plasticity and synaptogenesis (Knaus et al, 1986; Leclerc et al, 1989). Semi-quantitative Western blot experiments confirmed a 1.7- and 3.2-fold increase in cortex and hippocampus, respectively, but no significant alteration of striatal synaptophysin-1 content was seen (Figure 4). To provide evidence on the functionality of the vesicles, we then investigated the expression of the synaptic vesicle membrane protein, synaptobrevin 2 (also called as VAMP-2), and the soluble synaptosomal-associated protein of $25 \mathrm{kDa}$ (or SNAP-25, mostly located at the plasma membrane). Both proteins are known to have a key role in exocytosis by taking part in the formation of a fusion complex (Sudhof et al, 1993; Jahn et al, 2003). The regulation of these proteins by ALA treatment was evaluated by Western blot experiments on D10 in the cortical, hippocampal, and striatal structures. An approximate twofold increase in VAMP-2 levels was observed for both cortical and hippocampal regions (2.1- and 1.8-fold, respectively). No change was observed in the striatum (Figure 4). By Western blot analysis, SNAP-25 levels increased in ALA-treated mice only in the cortex (2.3-fold, Figure 4).

Another key factor in the regulation of the glutamatergic neurotransmission efficacy is the amount of glutamate that is transported into synaptic vesicles, which is determined by the level of expression of V-GLUTs (Fremeau et al, 2004; Iversen, 2006). Of the three known transporters, V-GLUT1 and V-GLUT2 are expressed prominently in the adult brain. V-GLUT1 predominates in the cerebral and cerebellar cortices, and in the hippocampus, whereas V-GLUT2 expression is prominent in diencephalon, brainstem, and spinal cord. As predicted, both V-GLUT isoforms were 

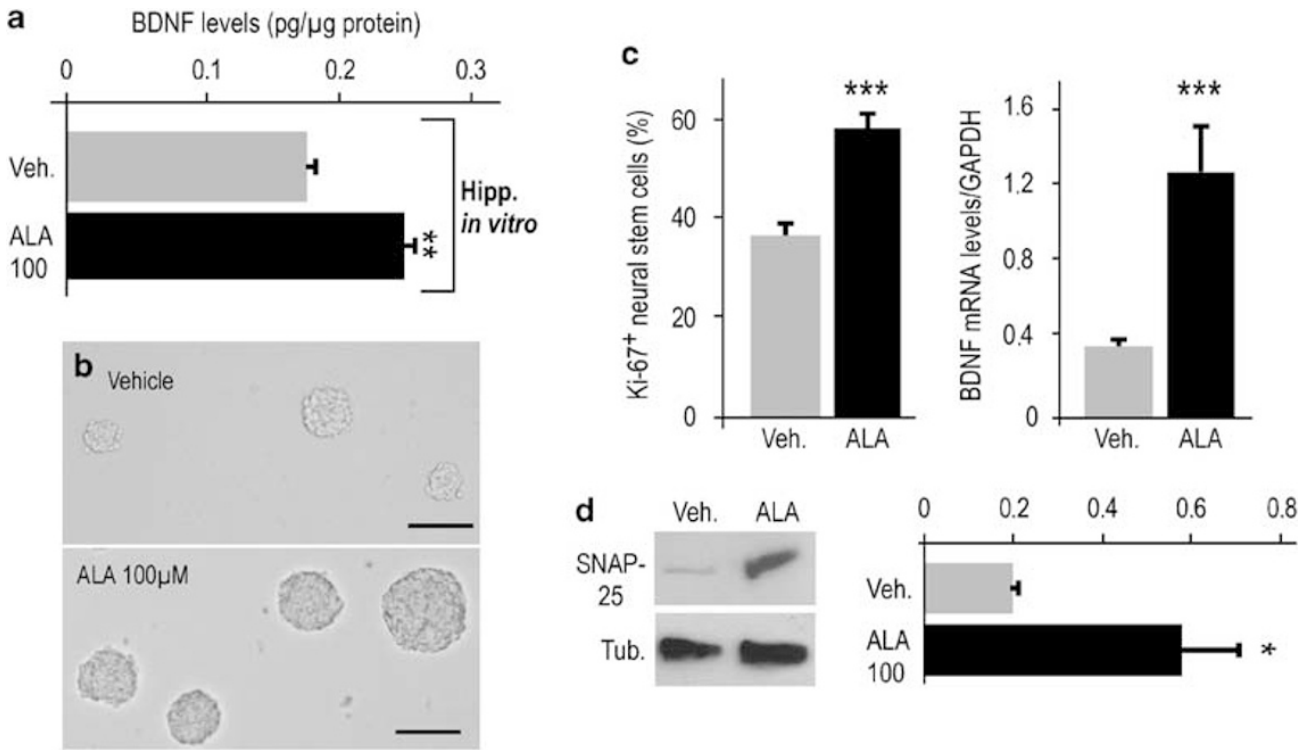

Figure 3 In vitro effect of ALA treatment on BDNF protein levels. (a) Increased BDNF protein levels under ALA treatment detected by ELISA in hippocampal neurons in culture. (b) Representative micrographs of NSC after ALA treatment (I00 $\mu \mathrm{M}$ ). Scale bar is $50 \mu \mathrm{m}$. (c) NSC proliferation identified by Ki-67 immunochemistry and BDNF mRNA expression (**** $<0.00 \mathrm{I}$ ). (d) Upregulation of SNAP-25 protein levels in NSC cultures treated using I00 $\mu$ M of ALA (*⿻ $p 0.05)$. ***** $\leqslant \leqslant 0.00$ I vs vehicle-treated mice.

upregulated in the cortex and hippocampus of the ALA500treated animals. V-GLUT-1 protein levels increased 14.3fold and 3.6-fold on D10 in the cortex and hippocampus, respectively (Figure 4, $p<0.05$ ). Again, no noticeable change was observed in the striatum. V-GLUT-2 was upregulated on D10 in the three brain structures examined (Figure 4).

\section{Subchronic ALA Treatment Induces Antidepressant- Like Behavior}

Knowing that a critical mechanism in the modulation of neuronal networks and antidepressant treatment response occurs through increased BDNF synthesis and its signaling pathways in brain, we tested the hypothesis that another protective contribution of ALA treatment could be an antidepressant effect. To this end, we performed the FST and the TST, two behavioral tests accepted as measures of antidepressant effects, on D7 and D10. When injected acutely, a single ALA injection had no antidepressant-like effect on either tests (Figure 5a and b). In contrast, three injections of ALA500 elicited a significant antidepressantlike effect, producing a 1.9- and 1.6-fold decrease in the FST immobility time on D7 and D10, respectively (Figure 5a, $(p<0.001))$. TST confirmed the same antidepressant-like effect induced by subchronic ALA500 treatment. As compared with vehicle-injected mice, subchronic ALA treatment induced a $35 \%$ decrease in the immobility time on D7 and D10 (Figure 5b, $p<0.001$ ). Figure $5 \mathrm{c}$ shows that the locomotor activity in ALA-injected mice was comparable with that observed in vehicle-treated mice $(p>0.05$, Figure 5c). This ensures that the increased active behaviors in FST are not secondary to a nonspecific increase in motor activity.
Pre- and Post-Treatments with Repeated ALA Injections Reduce, Respectively, Infarct Volume and Mortality Induced by MCAO

To determine whether pretreatment with repeated ALA500 injections protects mice against stroke injury, mice received three ALA500 injections on D1, D3, and D7, and were then subjected to transient MCAO on D10. Quantitative assessment of infarct volume $24 \mathrm{~h}$ after reperfusion reveals that this ALA pretreatment significantly reduced cerebral infarction as compared with results obtained in vehicleinjected ischemic mice $(p<0.01)$ (Figure $5 \mathrm{~d}$, right panel). In parallel, we confirmed in the in vitro model (hippocampal neurons in culture) that ALA application, which induced increased BDNF expression, significantly prevented glutamate-induced loss as compared with vehicle-treated $\left({ }^{\$} p<0.05\right)$ (Figure 5d, left panel).

Then we compared the effect of two post-treatments (single and repeated ALA500 injections) on the mortality rate obtained 10 days after reperfusion. Figure $5 e$ shows the severity of the MCAO, which caused a death rate of approximately $75 \%$ in the vehicle-injected ischemic mice within 10 days post-ischemia. As expected from our previous study (Heurteaux et al, 2006a), the single ALA500 injection failed to promote long-term survival. In contrast, the post-treatment paradigm with three repeated ALA500 injections (on D1, D3, and D7) resulted in a threefold improvement in the survival rate after 10 days of reperfusion compared with the single dose of ALA500 or the vehicle-only control (including single and repeated injections).

\section{DISCUSSION}

There is substantial evidence that omega-3 PUFA, including ALA, have therapeutic potentials in neurological and 


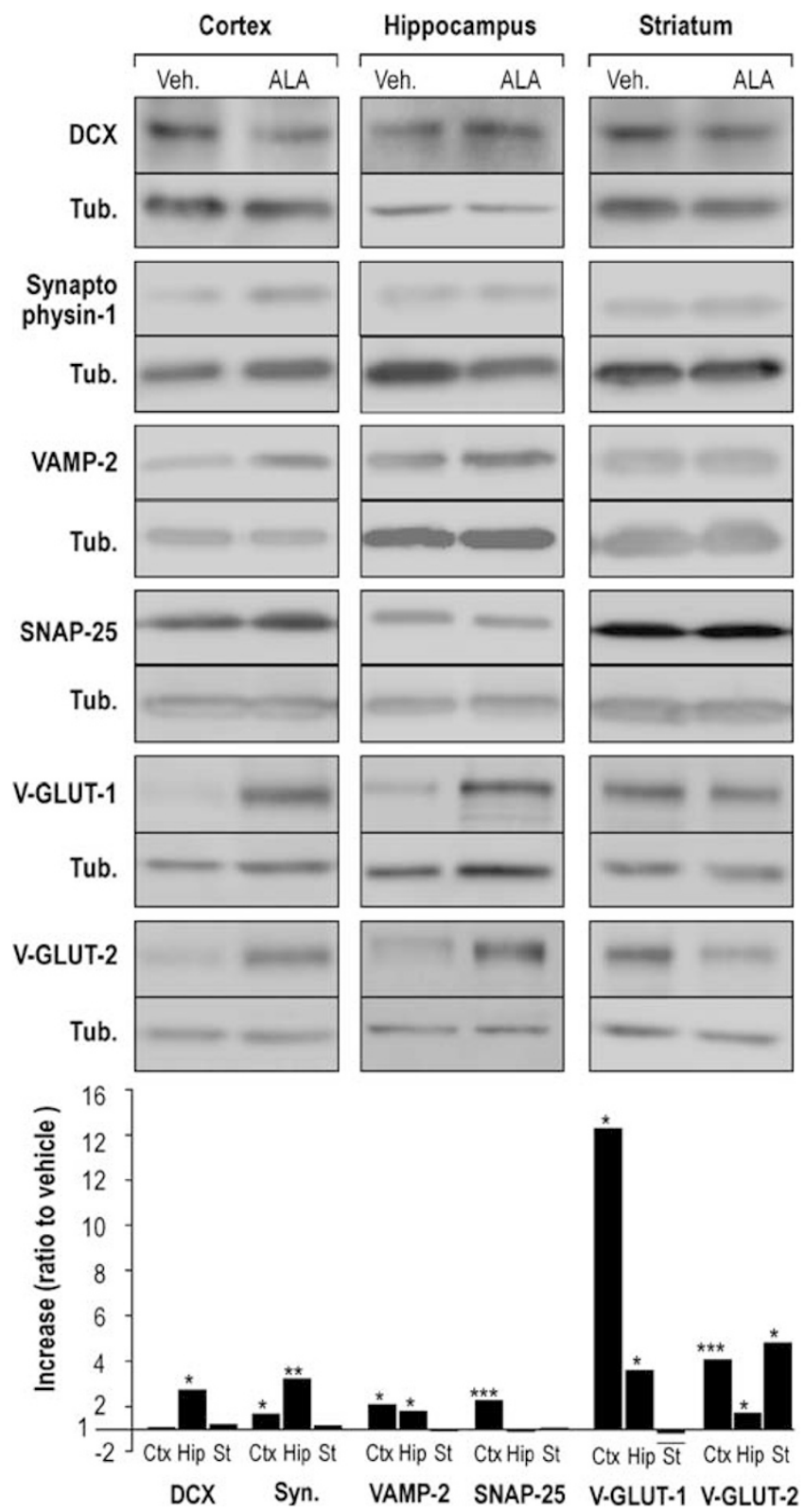

Figure 4 Effect of ALA treatment on levels of different markers of synaptogenesis in cortex, hippocampus and striatum at day 10. Western blotting using specific antibodies: DCX, synaptophysin, synaptobrevin-2 (VAMP-2), SNAP-25, and vesicular glutamate transporters (V-GLUT-I and -2). For each condition, representative result, from three independent experiments using six different samples (upper panel) are shown. The increased levels of specific proteins with ALA treatment are expressed as a ratio with the vehicle condition, normalized with $\alpha$-tubulin (lower panel). Statistics were calculated within each condition comparing the ALA treatment with its appropriated control, $n=6,(* p<0.05$, *** $p<0.01$, ***** $p<0.001$ ).

psychiatric disorders. Our laboratory previously showed a neuronal protection induced by acute ALA treatment in different models of ischemia (Lauritzen et al, 2000; Blondeau et al, 2001, 2002, 2007; Heurteaux et al, 2004, 2006a). The beneficial ALA effects have been reported to be, in part, because of its activating effect on neuronal potassium TREK 1 channel, preventing the excessive release of excitotoxic glutamate while favoring a magnesium ${ }^{2+}$ block at post-synaptic NMDA receptors. The importance of TREK-1 in cerebral protection against stroke has been validated by the fact that the ALA protective effects are strongly decreased in TREK-1-deficient mice (Heurteaux et al, 2004). In addition to the early and acute prevention of excitotoxicity induced by ALA treatment, we showed that ALA treatment increases cerebral blood flow and that this increase is related to an increased vasodilation leading to cerebral protection (Blondeau et al, 2007). The vasoactive ALA effect is also mediated by TREK-1 channels, because ALA-induced relaxation of cerebral arteries disappeared in TREK-1-deficient mice (Blondeau et al, 2007).

Several epidemiological studies suggest that the consumption of omega-3 PUFAs is inversely correlated to the prevalence and severity of depression, whereas recent clinical studies also provide evidence about the benefits of omega-3 PUFAs to treat depressive disorders (Freeman et al, 2006; Montgomery and Richardson, 2008; Owen et al, 2008). In animal models, ALA-enriched diet displays antidepressant-like activity in the FST and the TST (Carlezon et al, 2005; Huang et al, 2008; Venna et al, 2009), but antidepressant effects of acute ALA injection remained unknown.

Converging lines of evidence have shown that the mechanisms of antidepressants are related to several mechanisms of neuroplasticity, ranging from changes in gene expression (including neurotrophic mechanisms) to synaptic transmission and plasticity, and neurogenesis (Lemaire et al, 2000; Shors et al, 2001; Racagni and Popoli, 2008). Restorative therapies for experimental stroke substantially improve functional outcome. These therapies target several types of parenchymal cells, especially neurons and NSC, leading to enhancement of endogenous neurogenesis, axonal sprouting, and synaptogenesis in the ischemic brain (reviewed in Chopp et al, 2009). Interaction between these restorative events probably underpins the improvement in functional outcome.

Molecules able to trigger such mechanisms are appealing in the context of neuron repair and cognitive recovery after stroke. Therefore, this work addressed whether a subchronic ALA treatment using three sequential injections would (1) increase brain plasticity; (2) exert an antidepressant effect; and (3) enhance neuroprotection against stroke.

Subchronic ALA treatment significantly increased the number of proliferating immature neurons that survive and, at term, become mature. These results suggest that ALA promotes neurogenesis in the adult brain that could have a role in motor and cognitive functional recovery of neurological disorders.

Research activities focusing on NSC have shown that promoting their proliferation or grafting/infusing them by different routes into the brain leads to neurological improvement in different brain disease models, including stroke (Nomura et al, 2005; Pallini et al, 2005; Capone et al, 2007; Maysami et al, 2008). This benefit does not come only by their capacity to replace lost neurons. They can also trigger several other mechanisms, such as the induction of survival-promoting neurotrophic factors or promote the restoration of synaptic transmitter release function by integrating into existing synaptic network, and thus improve the functional circuitry. This work shows that subchronic ALA treatment promotes NSC proliferation. It is 


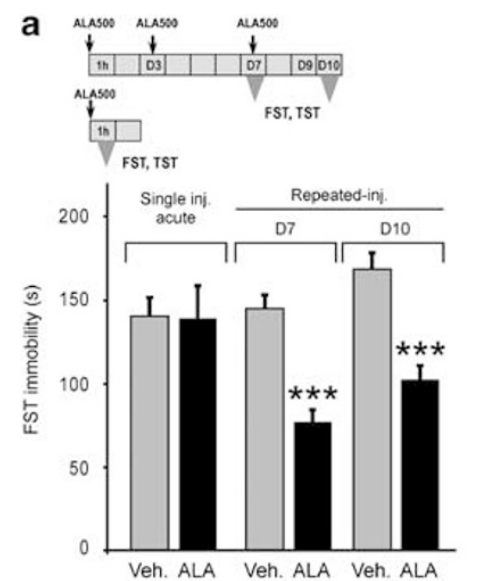

b
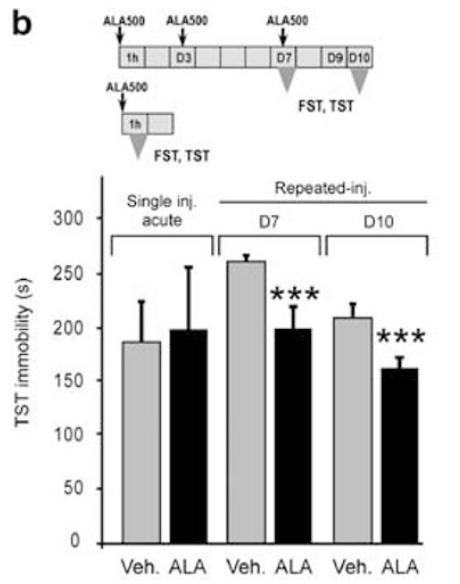
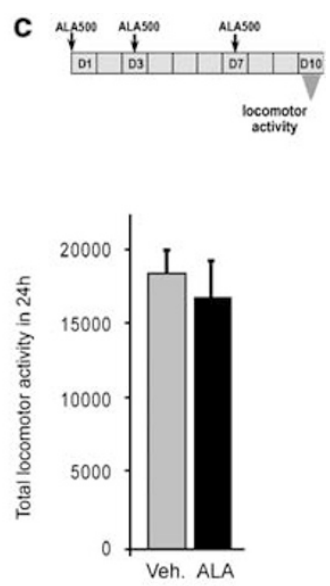
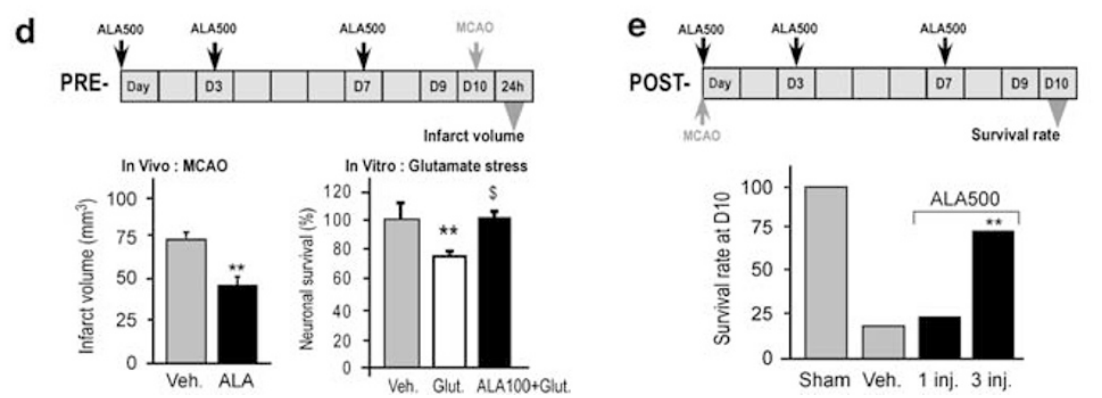

Figure 5 Effects of subchronic ALA treatment on depressive behavior and ischemic stroke. (a, b) Effect of ALA treatment on immobility time in Porsolt Forced Swim Test (FST) (a) and Tail suspension test (TST) (b). The immobility time was measured between vehicle and ALA-treated mice I h after a single ALA injection ( $n=8$ per experimental group) and I h or 3 days after the final dose of the subchronic ALA treatment (D7 and DI 0 , **** $<0.00 \mathrm{I})$ in another group $(n=14)$. (c) Total locomotor activity 3 days after the final dose of the subchronic ALA treatment (DI0). (d) ALA pretreatment protected from MCAO. Left panel: subchronic pretreatment consisted in injection of $500 \mathrm{nmol} / \mathrm{kg}$ alpha-linolenic acid (ALA500) at DI, D3, and D7 before MCAO (performed at DI0). At $24 \mathrm{~h}$ post-ischemia, the infarct volume was quantified in ALA-treated animals (ALA) and compared with those of vehicle-injected animals (Veh.), $\left(n=10,{ }^{*} * p<0.0\right.$ I). Right panel: ALA protection against glutamate excitotoxicity in hippocampal neurons. The I00 $\mu$ M concentration of ALA

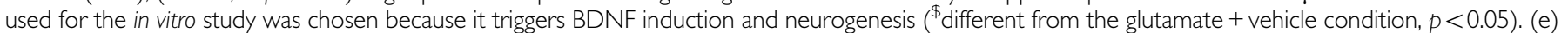
ALA post-treatment protected from MCAO. Subchronic ALA treatment was started $2 \mathrm{~h}$ after the reperfusion onset. The beneficial effect of ALA on animal survival rate at DIO is compared with subchronic vehicle treatment and a single ALA injection administered $2 \mathrm{~h}$ after the reperfusion onset (** $p<0.0 \mathrm{I}$ ).

worth noting that NSC can induce the transcription of protective factors, such as BDNF, which would be expected to modify the ischemic environment and promote neuroprotection. Our in vitro and in vivo studies show that the expression of BDNF levels was increased after ALA treatment, both in NSC, hippocampal mature neurons and in cortical/hippocampal tissue. BDNF is an immediate early gene that responds rapidly after membrane depolarization, and is involved in the maintenance and support of neurons (Barde, 1994; Marini et al, 2008). It is essential in neuronal survival and behavior-related plasticity (Lipsky and Marini, 2007). BDNF induces anti-apoptotic mechanisms after stroke, and reduces infarct size and secondary neuronal cell death (Schabitz et al, 2000; Zhang and Pardridge, 2001). It is also a potent stimulator of neurogenesis in intact and ischemic brains, leading to an improvement of the functional outcome after stroke. Consistent with the totality of BDNF mechanisms described above, our results suggest that ALA treatment induces a strong neurogenesis related to a direct regulation of enhanced neuronal BDNF expression on immature NSCs and mature hippocampal neurons in culture. Furthermore, the neurogenesis and the upregulation of mature BDNF triggered by ALA treatment, which occur together in neurons, can be considered as additional mechanisms that lead to increased brain protection and an environmental change favorable toward recovery of functional network circuitry.

Once we established the ALA-induced increase of neurogenesis along with enhanced BDNF protein levels, the next step was to determine whether subchronic ALA treatment stimulates synaptic plasticity and synaptogenesis by modulating proteins known to have a pivotal role in exocytosis. The significant increase of synaptophysin induced by repeated ALA injections indicates that subchronic ALA treatment promotes presynaptic plasticity and synaptogenesis. In most synapses of the mammalian brain, synaptic vesicle fusion is executed by a complex called SNARE, which is composed of synaptobrevin-2 (also named VAMP-2), syntaxin-1, and SNAP-25 proteins (Sutton et al, 1998). We used the modulation of expression of VAMP-2 and SNAP-25 in brain tissue as well as in NSC to determine the functionality of synapses. ALA treatment specifically increased the levels of VAMP-2 in cortex and hippocampus, but not in the striatum. SNAP-25 expression was also increased in cortex. The parallel increase of synaptophysin-1 and VAMP-2, two vesicle-associated synaptic proteins (SV-proteins) and their membrane-associated synaptic protein (PM-protein), SNAP-25, presents a strong argument 
in favor of an ALA-induced increase in synaptogenesis of the cortex.

Although ALA application on NSCs in culture induces a strong increase in SNAP-25, it represents in vivo an undersized part of the hippocampal cell. Moreover, ALAinduced SNAP-25 in NSC is probably associated with neuronal precursors, because SNAP-25 is absent in astrocytes in culture (Parpura et al, 1995; Jeftinija et al, 1997; Hepp et al, 1999), or expressed in only a small proportion of immature cells (Wilhelm et al, 2004). Therefore, from a mechanistic point of view, it is interesting to note that in the hippocampus, only the levels of SV-proteins (synaptophysin-1 and VAMP-2), but not of SNAP-25, are upregulated by subchronic ALA treatment. Several in vitro reports suggest that BDNF upregulates the levels of SV-proteins before those of PM-proteins. Furthermore, SNARE upregulation takes place more rapidly in cortical neurons than in those of hippocampus. Indeed, a 48-hr BDNF application to hippocampal slices solely augments the levels of synaptophysin and VAMP-2, but not of SNAP-25 (Tartaglia et al, 2001). In contrast, the increase in both SV- and PM-proteins was shown after a 5-day BDNF application to cortical neurons (Takei et al, 1997) and after a longer application (10 days) to hippocampal neurons in culture (Yamada et al, 2002). Our findings show a coherent temporal and spatial relationship between BDNF expression and ALA-induced changes in proteins involved in the fusion complex, suggesting that BDNF is a key mediator of the ALA treatment effect on synaptogenesis. This idea is also reinforced by the fact that BDNF regulates the density of spines (McAllister et al, 1995, 1996; Tyler and Pozzo-Miller, 2001; Alonso et al, 2004; Ji et al, 2005), explaining the intense immunostaining for SNAP-25 of the cortical circuitry that we find in the ALA500-treated animals.

The effects of subchronic ALA treatment on increased synaptogenesis and proteins levels involved in exocytosis are in good accordance with recent studies showing that interactions of SNARE proteins with PUFA are of critical importance in regulation of vesicle fusion (Darios et al, 2007; Davletov et al, 2007). As ALA treatment promotes synaptogenesis by modulating the level of SNARE complex, we finally analyzed whether ALA is able to increase the protein levels involved neurotransmitter release. We focused on glutamatergic neurotransmission, whose efficiency is reflected by the expression levels of vesicular glutamate transporters, V-GLUT1 and V-GLUT2. Subchronic ALA treatment induces the upregulation of both $\mathrm{V}$ GLUTs in cortex and hippocampus, suggesting that the omega-3 precursor ALA may promote the neurotransmitter glutamate release. As the cortex and hippocampus are two brain regions known to be crucially involved in synaptic plasticity, our findings suggest that subchronic ALA enhances plastic responses in these two brain regions.

It is plausible that an increase in the number of synapses and/or the upregulation of presynaptic machinery results in ALA-BDNF-potentiation of the neurotransmitter release that could have antidepressant effects. However, while the time course of the various markers of synaptogenesis after ALA treatment are supportive of a functional-anatomical relationship, it is also possible that the behavioral modifications might be due to the production of new neurons rather than modification of existing synapses. As we also showed that ALA might also induce BDNF synthesis by the NSCs, positive synergetic or additive effects have to be considered.

Another part of the present work is regarding the effect of repeated ALA injections in depression. Here, we show that subchronic ALA treatment induces an increase in BDNF levels, and improves neurogenesis and synaptic plasticity in specific brain regions, properties well known for the efficiency of antidepressant drugs (Castren et al, 2007). Using behavioral tests, FST and TST, this work shows that a single ALA injection does not induce antidepressant-like effects, whereas subchronic ALA treatment shows beneficial effects on preventing the development of depression-like behavior in mice in FST and TST paradigms. These results are in good accordance with the antidepressant-like effects of omega 3-enriched diet (Carlezon et al, 2005; Huang et al, 2008; Venna et al, 2009). Furthermore, the subchronic ALA treatment offers a shorter duration of treatment, as compared with diet and a long-lasting antidepressant-like effect, which is still observed 3 days after the final administered dose. It is known that antidepressant drugs have a positive effect on PSD by mediating the signaling pathways of brain plasticity (Santarelli et al, 2003; Dranovsky and Hen, 2006). Neurogenesis and synaptogenesis associated with subchronic ALA treatment are strong arguments in favor of such mechanisms involved in the ALA-antidepressant effect, which can also be related to additive/or synergic interactions with serotonin, norepinephrine, or dopamine pathways (Delion et al, 1994, 1996).

With regard to stroke and long-lasting efficiency of ALA on antidepressant behavior and neuroplasticity, we have independently tested whether a protection against ischemia will be observed 3 days after the final administered dose. Our results show that the subchronic ALA treatment is efficient as preventive treatment. The several protective effects of ALA on neurons (including reduction of excitotoxicity, neurotrophic factor induction, and microenvironmental-associated plasticity changes) may be difficult to interpret how neurogenesis, produced by subchronic ALA treatment before MCAO, reduces infarct volume. In contrast, it seems intuitive that post-MCAO, subchronic ALA treatment may restore neuronal loss, in part, by promoting neurogenesis. In addition, neurogenesis could affect the post-stroke recovery period, which represents yet another target for more efficient therapeutic effects. ALA treatment can be perceived as a 'restorative' intervention, which can explain the observed reduced mortality.

In this work, we show that subchronic ALA treatment enhances endogenous neurogenesis and synaptogenesis by a neuronal pathway. Given our previous findings of vasoactive ALA-properties (Blondeau et al, 2007) and increases in neurogenesis being associated with vascular changes (Palmer et al, 2000), we cannot exclude a facilitation of neurogenesis and synaptogenesis related to a vasculature-mediated effect of subchronic ALA treatment.

In summary, the present work shows that a subchronic treatment with ALA injections promotes several features associated with neurogenesis/synaptogenesis and possesses antidepressant-like qualities that may be beneficial for stroke recovery. This functional benefit may be related to acute increased vasodilation and excitotoxicity prevention, as well as long-term enhancement of neurogenesis, synap- 
togenesis, and neurotransmitter transmission. From a clinical point of view, this 'multitarget' effect of subchronic ALA treatment may represent a novel approach to stroke and depression. This multitargeted strategy may extend to other neurodegenerative and psychiatric disorders.

\section{ACKNOWLEDGEMENTS}

The authors are grateful to Dr Thierry Coppola for his helpful advice on the synaptogenesis portion of this work. This work was supported by the Centre National de la Recherche Scientifique (CNRS), the Groupe Lipides et Nutrition (GLN), ONIDOL, The Fondation pour la Recherche Médicale (FRM - allocation jeune équipe), the Fondation Coeur et Artères, the Fond National de la Recherche Scientifique de Belgique, and the Defense Brain and Spinal Cord Injury Program (DBSCIP) (HU-000106-0005).

\section{CONFLICT OF INTEREST}

The authors declare no conflict of interest.

\section{REFERENCES}

Alonso M, Medina JH, Pozzo-Miller L (2004). ERK1/2 activation is necessary for BDNF to increase dendritic spine density in hippocampal CA1 pyramidal neurons. Learn Mem 11: 172-178.

Alsina B, Vu T, Cohen-Cory S (2001). Visualizing synapse formation in arborizing optic axons in vivo: dynamics and modulation by BDNF. Nat Neurosci 4: 1093-1101.

Barde YA (1994). Neurotrophins: a family of proteins supporting the survival of neurons. Prog Clin Biol Res 390: 45-56.

Blondeau N, Petrault O, Manta S, Giordanengo V, Gounon P, Bordet $\mathrm{R}$ et al (2007). Polyunsaturated fatty acids are cerebral vasodilators via the TREK-1 potassium channel. Circ Res 101: 176-184.

Blondeau N, Widmann C, Lazdunski M, Heurteaux C (2001). Activation of the nuclear factor-kappaB is a key event in brain tolerance. J Neurosci 21: 4668-4677.

Blondeau N, Widmann C, Lazdunski M, Heurteaux C (2002). Polyunsaturated fatty acids induce ischemic and epileptic tolerance. Neuroscience 109: 231-241.

Capone C, Frigerio S, Fumagalli S, Gelati M, Principato MC, Storini C et al (2007). Neurosphere-derived cells exert a neuroprotective action by changing the ischemic microenvironment. PLoS ONE 2: e373.

Carlezon Jr WA, Mague SD, Parow AM, Stoll AL, Cohen BM, Renshaw PF (2005). Antidepressant-like effects of uridine and omega- 3 fatty acids are potentiated by combined treatment in rats. Biol Psychiatry 57: 343-350.

Castren E, Voikar V, Rantamaki T (2007). Role of neurotrophic factors in depression. Curr Opin Pharmacol 7: 18-21.

Chopp M, Li Y, Zhang ZG (2009). Mechanisms underlying improved recovery of neurological function after stroke in the rodent after treatment with neurorestorative cell-based therapies. Stroke 40: S143-S145.

Darios F, Connell E, Davletov B (2007). Phospholipases and fatty acid signalling in exocytosis. J Physiol 585: 699-704.

Davletov B, Connell E, Darios F (2007). Regulation of SNARE fusion machinery by fatty acids. Cell Mol Life Sci 64: 1597-1608.

Delion S, Chalon S, Guilloteau D, Besnard JC, Durand G (1996). alpha-Linolenic acid dietary deficiency alters age-related changes of dopaminergic and serotoninergic neurotransmission in the rat frontal cortex. J Neurochem 66: 1582-1591.
Delion S, Chalon S, Herault J, Guilloteau D, Besnard JC, Durand G (1994). Chronic dietary alpha-linolenic acid deficiency alters dopaminergic and serotoninergic neurotransmission in rats. J Nutr 124: 2466-2476.

Dranovsky A, Hen R (2006). Hippocampal neurogenesis: regulation by stress and antidepressants. Biol Psychiatry 59: 1136-1143.

Freeman MP, Hibbeln JR, Wisner KL, Davis JM, Mischoulon D, Peet $M$ et al (2006). Omega-3 fatty acids: evidence basis for treatment and future research in psychiatry. J Clin Psychiatry 67: 1954-1967.

Fremeau Jr RT, Voglmaier S, Seal RP, Edwards RH (2004). VGLUTs define subsets of excitatory neurons and suggest novel roles for glutamate. Trends Neurosci 27: 98-103.

Golanov EV, Reis DJ (1995). Contribution of cerebral edema to the neuronal salvage elicited by stimulation of cerebellar fastigial nucleus after occlusion of the middle cerebral artery in rat. J Cereb Blood Flow Metab 15: 172-174.

Gordon WA, Hibbard MR (1997). Poststroke depression: an examination of the literature. Arch Phys Med Rehabil 78: 658-663.

Hepp R, Perraut M, Chasserot-Golaz S, Galli T, Aunis D, Langley K et al (1999). Cultured glial cells express the SNAP-25 analogue SNAP-23. Glia 27: 181-187.

Heurteaux C, Guy N, Laigle C, Blondeau N, Duprat F, Mazzuca M et al (2004). TREK-1, a K+ channel involved in neuroprotection and general anesthesia. EMBO J 23: 2684-2695.

Heurteaux C, Laigle C, Blondeau N, Jarretou G, Lazdunski M (2006a). Alpha-linolenic acid and riluzole treatment confer cerebral protection and improve survival after focal brain ischemia. Neuroscience 137: 241-251.

Heurteaux C, Lucas G, Guy N, El Yacoubi M, Thummler S, Peng $\mathrm{XD}$ et al (2006b). Deletion of the background potassium channel TREK-1 results in a depression-resistant phenotype. Nat Neurosci 9: 1134-1141.

Hibbeln JR (1998). Fish consumption and major depression. Lancet 351: 1213.

Huang EJ, Reichardt LF (2001). Neurotrophins: roles in neuronal development and function. Annu Rev Neurosci 24: 677-736.

Huang SY, Yang HT, Chiu CC, Pariante CM, Su KP (2008). Omega3 fatty acids on the forced-swimming test. J Psychiatr Res 42: $58-63$.

Iversen L (2006). Neurotransmitter transporters and their impact on the development of psychopharmacology. Br J Pharmacol 147(Suppl 1): S82-S88.

Jahn R, Lang T, Sudhof TC (2003). Membrane fusion. Cell 112: 519-533.

Jeftinija SD, Jeftinija KV, Stefanovic G (1997). Cultured astrocytes express proteins involved in vesicular glutamate release. Brain Res 750: 41-47.

Ji Y, Pang PT, Feng L, Lu B (2005). Cyclic AMP controls BDNFinduced TrkB phosphorylation and dendritic spine formation in mature hippocampal neurons. Nat Neurosci 8: 164-172.

Jia H, Damush TM, Qin H, Ried LD, Wang X, Young LJ et al (2006). The impact of poststroke depression on healthcare use by veterans with acute stroke. Stroke 37: 2796-2801.

Jiang X, Tian F, Mearow K, Okagaki P, Lipsky RH, Marini AM (2005). The excitoprotective effect of $N$-methyl-D-aspartate receptors is mediated by a brain-derived neurotrophic factor autocrine loop in cultured hippocampal neurons. J Neurochem 94: 713-722.

Jorge RE, Robinson RG, Arndt S, Starkstein S (2003). Mortality and poststroke depression: a placebo-controlled trial of antidepressants. Am J Psychiatry 160: 1823-1829.

Knaus P, Betz H, Rehm H (1986). Expression of synaptophysin during postnatal development of the mouse brain. J Neurochem 47: 1302-1304.

Lang-Lazdunski L, Blondeau N, Jarretou G, Lazdunski M, Heurteaux C (2003). Linolenic acid prevents neuronal cell death 
and paraplegia after transient spinal cord ischemia in rats. J Vasc Surg 38: 564-575.

Lauritzen I, Blondeau N, Heurteaux C, Widmann C, Romey G, Lazdunski M (2000). Polyunsaturated fatty acids are potent neuroprotectors. EMBO J 19: 1784-1793.

Leclerc N, Beesley PW, Brown I, Colonnier M, Gurd JW, Paladino T et al (1989). Synaptophysin expression during synaptogenesis in the rat cerebellar cortex. J Comp Neurol 280: 197-212.

Lemaire V, Koehl M, Le Moal M, Abrous DN (2000). Prenatal stress produces learning deficits associated with an inhibition of neurogenesis in the hippocampus. Proc Natl Acad Sci USA 97: 11032-11037.

Lipsky RH, Marini AM (2007). Brain-derived neurotrophic factor in neuronal survival and behavior-related plasticity. Ann NY Acad Sci 1122: 130-143.

Lu B, Figurov A (1997). Role of neurotrophins in synapse development and plasticity. Rev Neurosci 8: 1-12.

Marini AM, Popolo M, Pan H, Blondeau N, Lipsky RH (2008). Brain adaptation to stressful stimuli: a new perspective on potential therapeutic approaches based on BDNF and NMDA receptors. CNS Neurol Disord Drug Targets 7: 382-390.

Mattson MP, Duan W, Guo Z (2003). Meal size and frequency affect neuronal plasticity and vulnerability to disease: cellular and molecular mechanisms. J Neurochem 84: 417-431.

Maysami S, Lan JQ, Minami M, Simon RP (2008). Proliferating progenitor cells: a required cellular element for induction of ischemic tolerance in the brain. J Cereb Blood Flow Metab 28: 1104-1113.

McAllister AK, Katz LC, Lo DC (1996). Neurotrophin regulation of cortical dendritic growth requires activity. Neuron 17: 1057-1064.

McAllister AK, Lo DC, Katz LC (1995). Neurotrophins regulate dendritic growth in developing visual cortex. Neuron 15: 791-803.

Montgomery P, Richardson AJ (2008). Omega-3 fatty acids for bipolar disorder. Cochrane Database Syst Rev 2: Art no: CD005169.

Naylor M, Bowen KK, Sailor KA, Dempsey RJ, Vemuganti R (2005). Preconditioning-induced ischemic tolerance stimulates growth factor expression and neurogenesis in adult rat hippocampus. Neurochem Int 47: 565-572.

Nomura T, Honmou O, Harada K, Houkin K, Hamada H, Kocsis JD (2005). I.V. infusion of brain-derived neurotrophic factor gene-modified human mesenchymal stem cells protects against injury in a cerebral ischemia model in adult rat. Neuroscience 136: $161-169$.

Owen C, Rees AM, Parker G (2008). The role of fatty acids in the development and treatment of mood disorders. Curr Opin Psychiatry 21: 19-24.

Pallini R, Vitiani LR, Bez A, Casalbore P, Facchiano F, Di Giorgi Gerevini V et al (2005). Homologous transplantation of neural stem cells to the injured spinal cord of mice. Neurosurgery 57: 1014-1025; discussion 1014-1025.

Palmer TD, Willhoite AR, Gage FH (2000). Vascular niche for adult hippocampal neurogenesis. J Comp Neurol 425: 479-494.

Parpura V, Fang Y, Basarsky T, Jahn R, Haydon PG (1995). Expression of synaptobrevin II, cellubrevin and syntaxin but not SNAP-25 in cultured astrocytes. FEBS Lett 377: 489-492.

Peet M, Murphy B, Shay J, Horrobin D (1998). Depletion of omega3 fatty acid levels in red blood cell membranes of depressive patients. Biol Psychiatry 43: 315-319.

Porsolt RD, Bertin A, Jalfre M (1977). Behavioral despair in mice: a primary screening test for antidepressants. Arch Int Pharmacodyn Ther 229: 327-336.

Racagni G, Popoli M (2008). Cellular and molecular mechanisms in the long-term action of antidepressants. Dialogues Clin Neurosci 10: $385-400$.
Santarelli L, Saxe M, Gross C, Surget A, Battaglia F, Dulawa S et al (2003). Requirement of hippocampal neurogenesis for the behavioral effects of antidepressants. Science 301: 805-809.

Schabitz WR, Sommer C, Zoder W, Kiessling M, Schwaninger M, Schwab S (2000). Intravenous brain-derived neurotrophic factor reduces infarct size and counterregulates $\mathrm{Bax}$ and $\mathrm{Bcl}-2$ expression after temporary focal cerebral ischemia. Stroke 31: 2212-2217.

Shors TJ, Miesegaes G, Beylin A, Zhao M, Rydel T, Gould E (2001). Neurogenesis in the adult is involved in the formation of trace memories. Nature 410: 372-376.

Sudhof TC, De Camilli P, Niemann H, Jahn R (1993). Membrane fusion machinery: insights from synaptic proteins. Cell 75: 1-4.

Sutton RB, Fasshauer D, Jahn R, Brunger AT (1998). Crystal structure of a SNARE complex involved in synaptic exocytosis at 2.4 A resolution. Nature 395: 347-353.

Takai N, Sasaoka K, Inoue K, Takahashi M, Endo Y, Hatanaka H (1997). Brain-derived neurotrophic factor increases the stimulation-evoked release of glutamate and the levels of exocytosisassociated proteins in cultured cortical neurons from embryonic rats. J Neurochem 68: 370-375.

Tang X, Falls DL, Li X, Lane T, Luskin MB (2007). Antigenretrieval procedure for bromodeoxyuridine immunolabeling with concurrent labeling of nuclear DNA and antigens damaged by $\mathrm{HCl}$ pretreatment. J Neurosci 27: 5837-5844.

Tartaglia N, Du J, Tyler WJ, Neale E, Pozzo-Miller L, Lu B (2001). Protein synthesis-dependent and -independent regulation of hippocampal synapses by brain-derived neurotrophic factor. $J$ Biol Chem 276: 37585-37593.

Tyler WJ, Pozzo-Miller LD (2001). BDNF enhances quantal neurotransmitter release and increases the number of docked vesicles at the active zones of hippocampal excitatory synapses. $J$ Neurosci 21: 4249-4258.

U.S. Dept of Health and Human Services (1999). Mental Health: A report of the Surgeon General. Rockville, MD: U.S. Dept of Health and Human Services, Substance Abuse and Mental Health Services Administration, Center for Mental Health Services, NIH, NIMH.

Venna VR, Deplanque D, Allet C, Belarbi K, Hamdane M, Bordet R (2009). PUFA induce antidepressant-like effects in parallel to structural and molecular changes in the hippocampus. Psychoneuroendocrinology 34: 199-211.

Wada T, Haigh JJ, Ema M, Hitoshi S, Chaddah R, Rossant J et al (2006). Vascular endothelial growth factor directly inhibits primitive neural stem cell survival but promotes definitive neural stem cell survival. J Neurosci 26: 6803-6812.

Wilhelm A, Volknandt W, Langer D, Nolte C, Kettenmann H, Zimmermann H (2004). Localization of SNARE proteins and secretory organelle proteins in astrocytes in vitro and in situ. Neurosci Res 48: 249-257.

Xiao YF, Wright SN, Wang GK, Morgan JP, Leaf A (1998). Fatty acids suppress voltage-gated $\mathrm{Na}+$ currents in HEK293t cells transfected with the alpha-subunit of the human cardiac $\mathrm{Na}+$ channel. Proc Natl Acad Sci USA 95: 2680-2685.

Yamada MK, Nakanishi K, Ohba S, Nakamura T, Ikegaya Y, Nishiyama $\mathrm{N}$ et al (2002). Brain-derived neurotrophic factor promotes the maturation of GABAergic mechanisms in cultured hippocampal neurons. J Neurosci 22: 7580-7585.

Yoshimura S, Takagi Y, Harada J, Teramoto T, Thomas SS, Waeber $\mathrm{C}$ et al (2001). FGF-2 regulation of neurogenesis in adult hippocampus after brain injury. Proc Natl Acad Sci USA 98: 5874-5879.

Zhang Y, Pardridge WM (2001). Neuroprotection in transient focal brain ischemia after delayed intravenous administration of brain-derived neurotrophic factor conjugated to a blood-brain barrier drug targeting system. Stroke 32: 1378-1384. 